\title{
A revista Paz e Terra: um lugar da memória da comunicação religiosa, ecumênica e política no Brasil
}

\author{
Paz e Terra journal: \\ a site (realm) of memory of religious, ecumenical and political \\ communication in Brazil
}

Magali do Nascimento Cunha*

\begin{abstract}
Resumo
Este artigo tem por objetivo examinar a relevância de produções de contrainformação desenvolvidas durante a ditadura militar no Brasil por grupos religiosos. O objeto é a revista Paz e Terra, da Editora Civilização Brasileira nos anos 1960, como iniciativa ímpar no campo da comunicação religiosa, ecumênica e política. A fim de se responder à questão-problema "qual o lugar da revista Paz e Terra na memória das produções midiáticas religiosas no Brasil?" são tomados por base estudos sobre "suportes da memória" e "lugares de memória". A articulação entre a narrativa da memória de Paz e Terra e a descrição do conteúdo dos dez exemplares publicados, que forma a metodologia da pesquisa empregada, foi feita com base no acervo da revista, em pesquisa documental, em depoimentos de personagens envolvidas, colhidos durante pesquisa para o Mestrado em Memória Social da autora, e em obras sobre a Editora Civilização Brasileira e seu editor Ênio Silveira, sobre as lideranças evangélicas envolvidas no projeto e sobre a própria revista. Busca-se, com este texto, contribuir com a ampliação das abordagens sobre os estudos em mídia, religião e política no Brasil, alargando o foco das análises críticas centradas em produções contemporâneas e aplicando a chave referencial da memória.
\end{abstract}

Palavras-chave: Religião. Mídia. Memória. Ditadura militar. Política.

\begin{abstract}
This article aims to examine the relevance of counter-information productions developed during the military dictatorship in Brazil by religious groups. The object is the journal Paz e Terra, by Editora Civilização Brasileira in the 1960s, as a unique initiative in the field of religious, ecumenical and political communication. In order to respond to the Research problem "what is the place of the journal Paz e Terra in the memory of religious media productions in Brazil?" the article refers its basis in studies on "memory supports" and "sites (realms) of memory" are based. The articulation between the narrative of the memory of Paz e Terra and the description of the content of the ten published issues, which form the methodology of the research employed, was made based on the collection of the magazine, in documentary research, in statements of characters involved, collected during the research project for a Master's Degree in Social Memory by the author, and in works about Editora Civilização Brasileira and its editor Ênio Silveira, about the Protestant leaders involved in the project and about the journal itself. This text seeks to contribute to the expansion of approaches to studies in media and religion in Brazil, broadening the focus of critical analysis centered on contemporary productions and applying the referential key of memory.
\end{abstract}

Keywords: Religion. Media. Memory. Military dictatorship. Politics.

Artigo submetido em 14 de fevereiro de 2020 e aprovado em 20 de agosto de 2020.

"Doutora em Ciências da Comunicação pela USP. Professora da UMESP. País de origem: Brasil. E-mail: magali.ncunha@gmail.com

Horizonte, Belo Horizonte, v. 18, n. 56, p. 513-541, maio/ago. 2020 - ISSN 2175-5841 


\section{Introdução}

O relatório final da Comissão Nacional da Verdade (2014), que investigou as violações de direitos humanos promovidas pelo Estado e seus segmentos, tornou explícitas as significativas demandas deixadas como herança à sociedade brasileira. No contexto desse período denominado "anos de chumbo" estão importantes processos de comunicação, tanto os muito especialmente marcados por censura e repressão empreendidos pelo governo militar e seus aliados, quanto aqueles desenvolvidos por grupos de oposição e resistência a ele.

Da parte do regime, foram articuladas ações comunicacionais, fundamentalmente caracterizadas como propaganda ideológica, com vistas a respaldar o governo ditatorial e controlar e censurar conteúdo educativo e de entretenimento que, no entender do aparelho repressivo, representasse ameaça à "segurança nacional". Silenciamento e apagamento de memórias, falsidades e injustiças foram marcas predominantes dessas ações comunicacionais governamentais, muitas delas com o apoio dos empresários das grandes mídias nacionais. Buscava-se a construção de apoio popular em torno da economia ("o milagre brasileiro") e a desmobilização política (GARCIA, 1990b).

Em oposição estavam grupos relacionados a diferentes segmentos sociais, colocando-se em resistência ao regime, em cujas ações estavam processos de comunicação alternativa, de contrainformação. Na afirmação de Ciro Juvenal Marcondes Filho, a contrainformação se expressa

a partir da análise e da crítica ao tipo de transmissão noticiosa existente, atomizada positivisticamente, uma transmissão e um tratamento de notícias institucionalmente, que não ofereça "informação" sem abstração, mas sim história e subjetividade real, que inclua e envolva as vivências, as necessidades e os interesses que emanam da própria vida dos que trabalham com ela. (MARCONDES FILHO, 1983, p. 5).

A contrainformação foi praticada no Brasil especialmente no período de censura do governo militar pós-1964 como polo de resistência social e política. Os diferentes segmentos de oposição trabalhavam com diferentes mídias, do teatro aos 
impressos e ao áudio, a maioria com circulação bastante limitada, dentro e fora do País. Destacaram-se os jornais tabloides e os boletins artesanais (conhecidos no início como "imprensa nanica") publicados por grupos e movimentos diversos (FESTA, 1986), entre estes, por exemplo, o jornal O Pasquim, semanário publicado entre 26 de junho de 1969 e 11 de novembro de 1991.

O alternativo da contrainformação dos anos pós-1964 estava no processo de produção, circulação e uso das mensagens. Era criação conjunta, construção de uma realidade distinta daquela apresentada nos meios majoritários. Muitos produtos eram inicialmente clandestinos ou semiclandestinos, mas depois puderam ser institucionalizados pela força do próprio movimento (TILBURG, 1989).

Nesta construção de uma realidade distinta, recriavam-se ações e ideias à luz de um passado de resistência. Com isto construía-se uma memória que emergia, e cujo sentido estava em iluminar o projeto de transformação que se buscava - utopia - com voz aos silenciados pelo sistema, propagação de diferentes narrativas da história vivida e denúncia de injustiças e crimes praticados pelo Estado (CAPARELLI, 1989).

Esta concepção do lugar das mídias de contrainformação e resistência, durante a ditadura militar no Brasil, conduz a uma compreensão de memória na forma trabalhada por Fentress e Wickham:

em si e por si, a memória é simplesmente subjetiva. Ao mesmo tempo, porém, a memória é estruturada pela linguagem, pelo ensino e observação, pelas ideias coletivamente assumidas e por experiências partilhadas com os outros. Também isso constrói uma memória social. (FENTRESS; WICKHAM, 1992, p. 20).

Nesse sentido é que se pode afirmar que a memória é um processo de construção. Não um elemento que está no passado à espera de ser evocado, mas algo dinâmico que moldado por lembranças e registros de um tempo ora vivido que estão em permanente interação com o presente. 
No caso dos grupos de resistência à ditadura no Brasil, a memória instituinte pelas mídias alternativas era um enfrentamento à memória oficial/instituída daquele período. Esta limitava os grupos e experiências de oposição à condição de subversivos, comunistas e terroristas. Esta memória alternativa logrou alcançar espaço e visibilidade, em um esforço contrário ao movimento de silenciamento e esquecimento liderado pelos setores dominantes no período. A postura contrária e alternativa à hegemonia da ditadura refletia as "organizações espontâneas" (FOUCAULT, 1984) vigentes na sociedade brasileira no período da ditadura militar. Eram centenas os grupos que se manifestavam e atuavam à margem dos setores hegemônicos. Esta atuação dava-se, predominantemente, por meio da contra-informação. E aqui se introduz o objeto deste estudo, as mídias impressas produzidas por grupos cristãos ecumênicos nos anos de chumbo no Brasil, um processo de comunicação alternativa e de resistência que teve importantes efeitos na reconstrução da democracia no País.

Em particular, este artigo se dedica ao estudo de uma dessas produções: a revista Paz e Terra, publicada pela Editora Civilização Brasileira, entre 1966 e 1969, com um total de dez exemplares. O objetivo é examinar a relevância da revista como iniciativa ímpar no campo da comunicação religiosa, ecumênica e política, a partir da questão-problema: "qual o lugar da revista Paz e Terra na memória das produções midiáticas religiosas no Brasil?”. Para alcançá-lo foi tomado por base o referencial teórico sobre "suportes da memória" e "lugares de memória", o que tornou possível o percurso metodológico ancorado na articulação entre a narrativa da história da revista e a descrição do acervo composto pelos dez exemplares publicados, alicerçado em pesquisa documental, nos depoimentos de personagens envolvidas e em produções científicas sobre a Editora Civilização Brasileira, sobre o editor Ênio Silveira, sobre as lideranças evangélicas criadoras do projeto e sobre a própria Paz e Terra.

Espera-se com este trabalho contribuir para os estudos sobre mídia, religião e política, em especial no que diz respeito às produções relacionadas aos evangélicos brasileiros, cuja ênfase predominante é de análise crítica deste grupo 
religioso, reflexo do conservadorismo que tem caracterizado sua presença nas mídias ${ }^{1}$. A memória da revista Paz e Terra e a singularidade do seu projeto, pode contribuir para uma compreensão mais plural do segmento evangélico brasileiro, também formado por grupos com engajamento político embasado em compromisso social e diálogo com os diferentes segmentos da esfera pública, estes com menos visibilidade.

\section{Mídias como suportes de memória}

O uso das letras foi descoberto e inventado para conservar a memória das coisas. Aquilo que queremos reter e aprender de cor fazemos redigir por escrito a fim de que o que se possa reter perpetuamente na sua memória frágil e falível seja conservado por escrito e por meio de letras que duram sempre. (Conde Guy apud LE GOFF, 1994, p. 450).

O valor e a contribuição da escrita e das palavras gravadas para conservação e disseminação de memórias tem sido reconhecido nos estudos históricos. A popularização da escrita contribuiu intensamente com o processo de construção da memória social, permitindo o acesso a informações e noções que não são fixáveis na memória de modo completo, simplesmente por meio da audição, tornando possível, por exemplo, registros na forma de calendários, atos financeiros e religiosos, decretos, julgamentos e decisões oficiais, mapas. Com isso, a escrita passa a ter duas funções principais quando relacionada à memória, como indica $\mathrm{J}$. Goody:

Uma é o armazenamento de informações, que permite comunicar através do tempo e do espaço, e fornece ao homem um processo de marcação, memorização e registro; a outra, ao assegurar a passagem da esfera auditiva à visual, permite reexaminar, reordenar, retificar frases e até palavras isoladas (GOODY apud LE GOFF, 1994, p. 433).

O surgimento da imprensa no século 16 potencializa todo este processo. A imprensa passa a ser o grande suporte da escrita, e os impressos, veículos de ampla circulação de conhecimento, o que tem relação com o período de desenvolvimento da ciência moderna. O texto e a escrita ganham valor muito superior ao que lhes

\footnotetext{
${ }^{1}$ As abordagens críticas da presença dos evangélicos nas mídias no Brasil ganharam intensidade e densidade nos anos 1980 com a obra de Assmann (1986).
} 
era dado até então (GLENISSON, 1961). Livros, atas, jornais, revistas, manuais, diários, registros os mais variados passam a fazer parte do cotidiano dos grupos sociais. A memória coletiva também vem a ser disseminada no século 18 com a criação das enciclopédias, compreendidas então como a reunião de pequenas memórias.

Foi neste contexto que foram criados os demais suportes de comunicação como a fotografia e o cinematógrafo, no século 19, que ao lado da capacidade criadora das artes plásticas e da construção de monumentos, compõem a memória das imagens, e provocam mais uma transformação no processo de construção da memória coletiva: "multiplica-a e democratiza-a, dá-lhe uma precisão e uma verdade visuais nunca antes atingidas, permitindo assim guardar a memória do tempo e da evolução cronológica” (LE GOFF, 1994, p. 466). Novos paradigmas se estabeleceram no século 20, primeiro com a televisão e a popularização do audiovisual, depois com o desenvolvimento da memória eletrônica, que vem, durante o século 21, revolucionando todos os demais suportes.

Este reconhecimento do lugar das mídias, destacado aqui, importa a este trabalho na medida em que esses suportes materiais contribuem para a conservação e a disseminação de memórias. E aqui se localiza uma dimensão da relevância da revista Paz e Terra. Entretanto, ampliando a reflexão, as páginas de Paz e Terra têm ainda outro sentido em relação à memória social: registram o pensamento de uma época, especialmente aqueles dos produtores da revista que selecionavam e editavam textos com reflexões densas, com base em seu engajamento social, crítico do status quo, estimulado pela religião, como se poderá ver adiante.

Ao mediar a relação dos sujeitos com as transformações do seu cotidiano, [os meios de comunicação] produzem no âmbito do senso comum sentidos para os processos históricos nos quais estes sujeitos estão inseridos, da mesma forma que participam da constituição das próprias subjetividades. (...) Constitui-se, assim, um verdadeiro "lugar de memória” da contemporaneidade. (RIBEIRO, FERREIRA, 2007, p. 7). 
Por isso, interessa a este estudo ressaltar o papel das mídias como componentes da construção de processos históricos, constituindo-se, portanto, lugares de memória relacionada às religiões e sua relação com a política.

\section{As mídias como lugares de memória}

A compreensão que embasa a reflexão em curso neste trabalho é a da memória como um processo de construção. Nesta perspectiva, a memória não é elemento a ser preservado, no sentido de estar pronta para ser evocada no momento em que o presente estabelecer. Pelo contrário, a memória é instituída por situações e experiências vividas e pode ser também herdada, não se relacionando exclusivamente ao que foi vivido fisicamente por uma pessoa ou um grupo. Isso quer dizer que a memória sofre flutuações que estão diretamente relacionadas ao momento em que ela é articulada ou expressa. É por isso que a memória não cessa de se transformar porque os grupos sociais mudam sem cessar.

A memória traz em si a possibilidade de vermos o presente, não como uma realidade fixa e imutável, como algo eterno, mas como um produto humano, como um momento de passagem, uma ponte através da qual o passado constrói o futuro. E é para o futuro que se volta, assim, essa memória ativa, afirmando o poder e a força da ação humana sobre sua própria história, desnaturalizando o tempo humano. (GUARINELLO, 1994, p. 188-189).

A partir destas premissas pode-se afirmar que aquilo que a memória individual grava, exclui ou relembra, é o resultado de um processo de organização/construção, que é, predominantemente, um fenômeno social. É o mundo no qual os indivíduos estão inseridos, que determina o desempenho da memória deles e fornece as categorias com as quais eles pensam.

Estas concepções levam ao segundo elemento fundamental para este estudo: os lugares de memória. O termo "lugares de memória" foi difundido especialmente a partir da obra de sete tomos organizada por Pierre Nora, a partir de 1994, intitulada Les Lieux de Mémóire. Nora afirma que os lugares de memória existiriam onde os simples registros são finalizados. Eles são os registros e também aquilo que os transcende, que está para além deles: o sentido simbólico que os 
próprios registros carregam - a sua aura. Esses lugares são os espaços de fixação da memória se fixou e atuam como novas formas de assimilar a memória, mesmo por aquelas pessoas que nunca viveram o que ali está narrado: contribuem para a produção de memórias herdadas. São, portanto, onde grupos sociais se identificam e podem ser identificados.

os lugares de memória nascem e vivem do sentimento de que já não existe memória espontânea, que é preciso criar arquivos, que é preciso manter aniversários, organizar celebrações, pronunciar elogios fúnebres, registrar atas, porque essas operações não são naturais. (...) Se vivêssemos verdadeiramente as lembranças que eles envolvem, eles seriam inúteis. $\mathrm{E}$ se em compensação, a história não se apoderasse deles para deformá-los, transformá-los, sová-los e petrificá-los eles não se tornariam lugares de memória. É este vai-e-vem que os constitui: momentos de história arrancados do movimento de história, mas que lhe são devolvidos. (NORA, 1993, p. 13).

Trazer à reflexão os lugares de memória significa afirmar não o predomínio da integração, da estabilidade e da durabilidade da memória coletiva, mas sim a existência de uma pluralidade de memórias, construídas por diferentes grupos sociais e instituições. Maurice Halbwachs (1925) havia identificado a existência de uma pluralidade de memórias e as definiu por meio da expressão "quadros sociais da memória”, conceituados como os instrumentos dos quais a memória coletiva se serve para recompor uma imagem do passado que é recordada em cada época com os pensamentos dominantes da sociedade.

Neste sentido, para Halbwachs, o movimento de rememoração é uma construção de um passado, por meio da inteligência e do grupo social. As lembranças pessoais seriam reconstruídas, a partir dos próprios meios que as fixaram. A partir daí é que se poderia afirmar que há uma pluralidade de memórias coletivas, assim como há uma pluralidade de estruturas sociais (classes, instituições, subgrupos), que refletem aquilo que se quer conservar ou mudar. Daí a memória instituída ser permanentemente tensionada pelo movimento instituinte de novas memórias e das linguagens que envolvem este processo de instituição (RIVERA, 2018). 
No entanto, o que Pierre Nora indica é que também estes grupos e instituições fazem destas memórias distintas valores para serem utilizados como fins de poder e disputa em conflitos sociais. Para Nora a história estaria sob a pressão dessas memórias coletivas e desta forma, a memória não seria um espaço harmônico, uniforme ou homogêneo, onde reinaria absoluta uma só representação do passado, como a memória nacional. Diferentemente, haveria uma gama de distintas memórias particulares, de distintos grupos, com distintas formas de representar o passado, demonstrando assim, que a memória, bem como a identidade de um grupo social, pode ser ressignificada, experimentar mudanças e criações (GUARINELLO, 1994).

Trata-se exatamente da acepção de que no processo de construção da memória há seleção, escolha, ou seja, a compreensão de que nem tudo fica gravado, nem tudo fica registrado. O momento vivido é que vai determinar a forma pela qual a memória de um indivíduo ou de um grupo será estruturada. A isso se refere Jacques Le Goff, quando afirma:

A memória, como propriedade de conservar certas informações, remetenos em primeiro lugar a um conjunto de funções psíquicas, graças às quais o homem pode atualizar impressões ou informações passadas, ou que ele representa como passadas (LE GOFF, 1994, p. 423).

Isto significa que há memória social porque há significações construídas, isto é, há possibilidade de construção (atribuição de significações) para o grupo que recorda. As memórias partilhadas e o processo de partilha, ou seja, a produção das narrativas referentes ao presente ou ao passado, por meio dos suportes, tomam forma dentro do quadro de significados que lhes é dado pelo grupo no seio do qual serão contadas.

É neste sentido que se afirma neste trabalho o olhar sobre as mídias como lugares de memória: os processos comunicacionais midiáticos como lugares de registro, de arquivamento, de propagação de narrativas. Por intermédio das mídias a memória coletiva deixa de ser matéria somente de museus, arquivos, monumentos e túmulos. Além das mídias veicularem narrativas sobre o passado de 
uma coletividade, elas registram os sentidos do presente que, uma vez vivido por este coletivo, é elemento instituinte de novas memórias, ou seja, são lugares componentes processo de construção da memória social.

Paz e Terra pode ser entendida, portanto, como um lugar de memória do grupo religioso que a produziu no período da ditadura militar no Brasil e é dessa forma que ela passa a ser aqui estudada.

\section{Os três anos de revista Paz e Terra e o enfrentamento da ditadura}

Identificada como uma publicação da Editora Civilização Brasileira, dirigida por Ênio Silveira, a revista Paz e Terra, editada de 1966 a 1969, tem origem e produtores que marcam sua existência em perspectiva mais ampla. A própria história da revista representa a memória de dois segmentos do campo religioso no Brasil, os evangélicos e o movimento ecumênico, e, ao mesmo tempo, dos obstáculos vividos por lideranças relacionadas à educação e à comunicação no período da ditadura militar.

[...] a memória coletiva é realmente a memória do grupo: religioso, da classe social, da família, etc. Cada grupo tem caraterísticas próprias, mas, sempre será grupo de suporte indispensável para a memória. A memória familiar tem retratada sua densidade afetiva, sua irreversibilidade e sua forte continuidade. A memória religiosa é entremeada com conflitos, pois, diferentes das outras, tende a ser exclusiva. (RIVERA, 2018).

\subsection{Os evangélicos brasileiros, o movimento ecumênico e a responsabilidade sociopolítica cristã}

Quando se fala de "evangélicos" no Brasil, a referência em geral é feita ao conjunto de cristãos não vinculados à Igreja Católica Romana e a igrejas do ramo ortodoxo presentes no País. A consciência de que este conjunto é formado por uma diversidade muito ampla de grupos os mais distintos está presente na academia, entre os estudiosos das ciências humanas e sociais voltados para o fenômeno das religiões, e entre alguns poucos segmentos de mídia preocupados em informar o mais correta e objetivamente possível quando o noticiário envolve tal segmento. 
Daí as diferentes tipologias que foram e vêm sendo criadas e recriadas para dar conta de tal diversidade. No entanto, correntemente, fala-se de "evangélicos" englobando todos os não católicos e não ortodoxos em um só grupo quando se leva em conta a presença destes grupos religiosos na esfera pública, marcadamente no que diz respeito ao crescimento numérico, à presença na política, a movimentos culturais.

A imagem dos "evangélicos" que dá o tom desta compreensão corrente no País foi construída com base na identidade de dois grupos de cristãos não católicos: os protestantes de diferentes confissões que chegaram ao Brasil por meio de missões dos Estados Unidos, a partir da segunda metade do século 19, e os pentecostais, que aportaram em terras brasileiras na primeira década do século 20, vindos daquele mesmo país. Os grupos protestantes que alcançaram o Brasil por meio de imigração, luteranos e anglicanos, construíram uma identidade própria nesta realidade, com aberturas significativas, na segunda metade do século 20, à contextualização/inculturação, caso da Igreja Evangélica de Confissão Luterana, e têm imagem estreitamente relacionada a esta característica (MENDONÇA, 1984).

Fato é que a imagem construída em torno do nome "evangélico", majoritariamente centrada nas práticas e ideias do protestantismo missionário do sul dos Estados Unidos e do pentecostalismo embranquecido, mostrava ao Brasil um segmento cristão predominantemente: conservador teologicamente, fundamentalista e puritano; desprovido de tradição litúrgica, com prática centrada na palavra e pouca ou nenhuma ênfase na comunicação visual e/ou simbólica; rígido em relação aos prazeres do corpo e à moralidade cotidiana, por meio de um rompimento com expressões culturais brasileiras; anticatólico e sectário (CUNHA, 2007).

Algumas tentativas de superação deste quadro por uma presença pública mais intensa se concretizaram por meio de ações de assistência social realizada por parcelas da liderança evangélica e o movimento ecumênico brasileiro (unidade dos cristãos em torno de causas comuns) que culminou com a criação da Confederação 
Evangélica do Brasil (CEB, 1934), associação das principais igrejas evangélicas (Presbiteriana, Metodista, Luterana, Congregacional). A abertura de pessoas e grupos do Brasil para o contato com as expressões de cooperação, também em nível internacional, despertou para a "responsabilidade sociopolítica dos cristãos”, que estimulou uma atuação protestante para além das fronteiras confessionais.

O ápice desta dinâmica se manifestou nos anos de 1950 e 1960 e foi interrompido por uma reação conservadora das cúpulas, reforçadas pelo golpe militar de 1964, que desencadeou um processo repressivo na vida do País, inclusive nas igrejas (CNV, 2014). Isto repercutiu na forma de expurgos e perseguições aos secretários dos departamentos da CEB, a professores e alunos dos seminários teológicos, às organizações de juventude. Dentre as lideranças evangélicas atingidas pela censura, houve quem conseguisse sobreviver à repressão (interna e externa às igrejas) e buscasse espaços para garantir a sobrevivência das novas significações que emergiram, a fim de, ainda que na marginalidade, trabalhar para instituí-las. Um desses espaços foi o Centro Evangélico de Informação (CEI), criado em 1964, transformado em Centro Ecumênico de Informação, em 1965.

O fato de os remanescentes da CEB terem criado um "centro de informação" reflete as reflexões de Marcondes Filho (1983) e Tilburg (1989), citadas na introdução deste artigo, que enfatizam a contrainformação com intensa atividade de resistência social durante os anos pós-1964.

Em operação até 1975, o CEI reunia ex-lideranças da CEB, pastores e leigos, teólogos e estudantes, jovens e adultos que se identificavam com os ideais de unidade e de responsabilidade sociopolítica dos cristãos. Além de publicações com conteúdo relacionado à responsabilidade sociopolítica dos cristãos, o CEI, já na sua fundação, desenvolveu projetos e articulações ecumênicas para além das igrejas. Assim como indica Tilburg (1989), o CEI inicialmente operou de forma semiclandestina, mas logrou alcançar sua institucionalização pela força do próprio movimento. Internamente, os seminários e reuniões de estudo promovidas pelo CEI, que começaram com pessoas das igrejas, foram, no decorrer do tempo, se 
ampliando e reunindo pessoas do mundo secular. Nas recordações do sociólogo oriundo da Igreja Presbiteriana Waldo César, que, na CEB, foi secretário executivo do Setor de Responsabilidade Social da Igreja consta que:

O Márcio Moreira Alves foi um que entrou no nosso circuito, outro foi Lauro Oliveira Lima, a Rose Marie Muraro... essa rede foi crescendo e era formada por vários núcleos. Era o tempo da JEC, JUC, e de vez em quando a gente se encontrava em algum lugar. Eu fui a muitas reuniões de dois ou três dias em Petrópolis. Surgiam muitas coisas que refletiam nas publicações católicas. Essa rede nunca morreu e existiu durante todo o processo. Era uma rede de resistência mesmo e que toma um corpo mais concreto com a revista Paz e Terra. (CUNHA, 1997, p. 174).

A revista Paz e Terra surgiu de uma proposta no grupo do CEI, no processo de consolidação de suas atividades, de criar uma revista ecumênica de conteúdo aprofundado. O também sociólogo Luiz Eduardo Wanderley uniu-se a Waldo César à frente do projeto, e os dois decidiram contatar uma editora que pudesse possibilitar a sua realização. Foi a Ênio Silveira e à Editora Civilização Brasileira que as lideranças do CEI apresentaram a proposta de publicação da revista.

\section{2 Ênio Silveira e a Editora Civilização Brasileira}

Quando o grupo do CEI procurou a Civilização Brasileira e seu diretor para a realização do projeto da revista, a editora estava no auge da produção de publicações que a identificavam como uma das maiores casas publicadoras do Brasil (HALLEWELL, 2005). Dirigida, desde 1963, pelo sociólogo filiado ao Partido Comunista Brasileiro (PCB) Ênio Silveira (1925-1996), a Civilização Brasileira $^{2}$, valorizava, de forma entusiástica, autores da moderna literatura nacional, como Fernando Sabino, Antônio Callado e Millôr Fernandes, e traduzia literatos e pensadores considerados revolucionários na época, como James Joyce, Morris West, George Orwell, Bertold Brecht, Franz Kafka.

A Civilização Brasileira se destacava no país pelo seu catálogo marcado pela ousadia dos ideais progressistas do intelectual Ênio Silveira, com o lema "Quem

2 A Civilização Brasileira, fundada em 1929, havia sido comprada pela Companhia Editora Nacional em 1932 e administrada como subsidiária no Rio de Janeiro, para edições, fundamentalmente, de livros para adultos. Ênio Silveira iniciou sua carreira na Companhia Editora Nacional, em 1944, tendo assumido a direção da subsidiária em 1951 (HALLEWELL, 2005). 
mal lê, mal fala, mal ouve, mal vê". Isto pode ser constatado na lista de assuntos que a editora publicava: psicologia popular e educação, filosofia, ioga e zenbudismo, história, assuntos da atualidade, antropologia, sociologia, economia e política - estes três últimos os que mais marcaram a identidade da Civilização Brasileira com expressões do pensamento de esquerda, bem próximos do que defendia Ênio Silveira. Em 1965, foi criada a Revista Civilização Brasileira, marco do pensamento político e cultural e de resistência à ditadura militar, que publicou 21 números até 1968, quando foi censurada após o Ato Institucional $n^{0} 5$.

Ênio Silveira é considerado uma das personalidades mais influentes do meio editorial brasileiro, principalmente durante a ditadura militar. Em 1968, Silveira teve os direitos políticos suspensos por dez anos, e entre 1964 e 1969, foi preso sete vezes por conta de sua filiação ao PCB e pelas ações políticas e de resistência que empreendia no campo editorial. Pela diversidade de abordagens publicadas pela Civilização Brasileira, Ênio Silveira revelava-se um intelectual comunista, ateu, afinado com o pensamento progressista do seu tempo e aberto às possibilidades de expressão que estivessem em sintonia diferente com as bases sua formação. Silveira era estimulado e entusiasmado por conteúdos humanistas, que primavam pela liberdade humana e pelo bem-comum (FÉLIX, 1998). A abertura à publicação da revista Paz e Terra e às expressões do movimento ecumênico brasileiro liderado por evangélicos, é forte ilustração disto, o que Waldo César associou a um "bemhumorado ateísmo" (In FELIX, 1998, p. 416) e ao clima fraterno que permeou o relacionamento do grupo de produção:

Ali a gente descobriu uma conexão que foi muito mais rica do que dentro da Igreja. Eu tive uma relação muito mais fraternal com esse grupo do que com aqueles velhos setores da Igreja (...). Estávamos numa luta comum, pela justiça social, reforma agrária... Era uma revista de altíssima qualidade editorial. (CUNHA, 1997, p. 175).

\subsection{O projeto da revista Paz e Terra}

Na perspectiva ecumênica que marcava a identidade do CEI, o nome Paz $e$ Terra foi inspirado na Encíclica do Papa João XXIII intitulada Pacem in terris, publicada em 11 de abril de 1963. João XXIII, por meio do Concílio Vaticano II que 
convocou, estava abrindo as portas da Igreja Católica para a sociedade e para o diálogo com as demais igrejas cristãs e religiões (ecumenismo). Na carta, João XXIII enfatizava a necessidade da paz mundial e da contribuição da Igreja Católica junto com as demais igrejas e outras religiões, para o seu alcance. Na memória de Waldo César:

[O Ênio Silveira] ficou encantado com a ideia e nos mandou procurar o Moacyr Félix, que trabalhava com ele, e que vibrou com a ideia. Fizemos um projeto e dissemos a ele que deveríamos ter nomes de peso da Igreja Católica e do mundo secular, para que ninguém metesse a mão na revista. Com nomes como Alceu Amoroso Lima e D. Helder Câmara, esquerda lúcida e combatente, [a censura] não barraria a revista tão facilmente. Era uma estratégia. (CUNHA, 1997, p. 174).

Moacyr Félix, intelectual, poeta e um dos editores da Civilização Brasileira, era também afinado com o pensamento de esquerda e com os movimentos de oposição ao regime militar. Ligado ao PCB, como Ênio Silveira, foi preso em 1966 por conta de suas manifestações pela liberdade de expressão. Em depoimento, Félix recorda:

Tivemos que fazer [a revista], porque eles [o grupo do CEI] queriam ter uma série de ideia deles. A Revista da Civilização Brasileira ficou muito marcada como socialista, aberta, mas dentro de uma linha materialista. Nós queríamos mostrar que colaborávamos também com eles, dentro de qualquer linha de humanismo. Lutou pela liberdade, pela humanização da vida, contra a alienação, tem consciência de que este mundo está desumanizado, quer um mundo qualitativamente transformado num mundo melhor? Estamos de acordo, vamos expor suas teorias. (RIDENTI, 2000, p. 134).

A opção pelo nome Paz e Terra, ao invés de "Paz na Terra" (como na Encíclica), significava afinar a temática ainda mais com o pensamento da esquerda humanista, como explicitado na apresentação do primeiro número da revista: “A terra não é mais o isolamento, o fim de suas buscas e pesquisas, e sim o lugar onde o homem se afirma, transformando o mundo, acelerando a história, colocando a seu serviço todas as forças disponíveis” (PAZ E TERRA, n. 1, 1966, p. 3).

A nova publicação seguia o formato da revista Civilização Brasileira. O primeiro número, que apresentava Waldo César como diretor responsável, e Moacyr Félix como secretário, registrou estas ênfases na apresentação: 
Paz e Terra é o campo onde os humanismos, as igrejas e os diálogos dos homens de boa-vontade superam as diferenças de estrutura e instituição, raça e credo, cultura e partido, para se encontrarem no reconhecimento da necessidade de defender e promover os valores que se ligam à dignidade e à grandeza da vocação do homem. (PAZ E TERRA, n. 1, 1996, p. 1).

O Conselho de Redação da revista era composto por acadêmicos e religiosos relacionados ao Centro Ecumênico de Informação (CEI) e a grupos progressistas evangélicos e católico-romanos, e expressava bem o nível do conteúdo que seria ali exposto. São eles: Alceu de Amoroso Lima [Tristão de Athaíde], acadêmico, literato; Alfredo Bosi, acadêmico, literato; Antônio Otávio Cintra, acadêmico, sociólogo; Bernardo Catão, frei dominicano; Brenno Schumann, pastor luterano; Celso I. de Sylos, padre católico; Edgar de Godoy Matta Machado, ex-seminarista católico, deputado federal pelo MDB/MG cassado em 1968; Esdras Borges Costa, líder ecumênico, sociólogo; Francisco Guimarães, padre católico; Francisco Whitacker Ferreira, arquiteto e urbanista, assessor da CNBB; Glauco Soares de Lima, pastor anglicano; Jânio de Freitas, jornalista; João Dias de Araújo, pastorpresbiteriano, acadêmico, teólogo; Jorge César Mota, pastor presbiteriano, liderança de juventude evangélica; José Honório Rodrigues, acadêmico, historiador; José Paulo Moreira da Fonseca, pintor e poeta; Jovelino Pereira Ramos, pastor presbiteriano, acadêmico, teólogo; Lúcia Ribeiro de Souza, socióloga; Luiz Alberto Gomes de Souza, sociólogo, liderança de juventude católica; Luiz Eduardo Wanderley, sociólogo, liderança de juventude católica; Maria Helena Kühner, filósofa e dramaturga; Maria José Brandão Machado, educadora; Pedro Secondi, frei dominicano; Raul Landim Filho, acadêmico, filósofo.

A perspectiva de um ecumenismo fora das estruturas das igrejas, existente no CEI, trazida pelas pessoas oriundas da CEB e, em especial, do Setor de Responsabilidade Social do organismo, encontrou extensão por meio da experiência da revista Paz e Terra. No bojo da proposta estava a promoção de um diálogo entre pensadores cristãos destacados no Brasil e no exterior e entre esses pensadores e os leitores identificados com o "humanismo cristão". Não por acaso a palavra "diálogo" é exaustivamente citada no primeiro número da revista: 
a) já no subtítulo de capa, que passa a ser publicado em todos os exemplares da revista: "Paz e Terra. Ecumenismo e humanismo. Encontro e Diálogo";

b) nos dois textos de apresentação ("Nota da Direção" e "Paz e Terra”);

c) no primeiro artigo, de Alceu Amoroso Lima, intitulado "Diálogo da igreja [católica] com o mundo moderno".

Esta dimensão da proposta era explicitada pelos seus promotores em espaços abertos, como no texto de um anúncio da nova revista Paz e Terra publicada no verso da contracapa da revista Civilização Brasileira, n. 8, de julho de 1966:

Qualquer que seja a sua crença, se você luta ao lado dos que desejam um mundo melhor, Paz e Terra é a sua revista.

Se v. é um cristão que busca o diálogo com os tempos modernos, Paz e Terra é sua revista.

Se v. quer entre os brasileiros uma fraternidade atuante, no espírito do II Concílio Ecumênico [o Vaticano II], Paz e Terra é a sua revista. Procure-a nas boas livrarias.

A decisão de editar a revista levou Ênio Silveira a criar, de imediato, a Editora Paz e Terra, que deveria seguir a mesma política editorial, promotora do humanismo cristão progressista. No primeiro número da revista Paz e Terra foi publicado na pós-capa um anúncio que indicava isto:

Uma nova editora a serviço da cultura e do humanismo

PAZ E TERRA

iniciará proximamente suas atividades editoriais lançando os seguintes livros, representativos das mais importantes correntes do pensamento contemporâneo

Cristo e Cultura

Richard Niehbur

A igreja, o fascismo e a guerra

Primo Mazzolari

Marxismo, existencialismo e personalismo

Jean Lacroix

A técnica e o desafio do século 
Jacques Ellul

O Cristianismo e a realidade brasileira

Diversos autores

Do anátema ao diálogo

Roger Garaudy

Ainda no primeiro número, o verso da contracapa também trazia um anúncio que demarcava bem o terreno no qual a revista e a editora Paz e Terra almejavam transitar.

World Conference

on Church and Society

Genebra, 12-26 de julho de 1966

A Editora Paz e Terra Ltda.

tem o prazer de informar ao público interessado em problemas sociais que entrou em entendimento com os organizadores desse importante conclave para publicar, em português, os quatro livros que nortearão o seu trabalho:

- Christian social ethics in a changing world

- Responsible government in a revolutionary age

- Economic growth in world perspective

- Man in community ${ }^{3}$

Com o desenvolvimento da editora, textos de publicações ecumênicas eram traduzidos, artigos e livros de teólogos de destaque, ignorados por outras editoras, eram publicados, abordagens diversificadas de intelectuais brasileiros eram divulgadas. Em 1968 a editora Paz e Terra já havia publicado 16 títulos e em 1969, 25, em pleno período de endurecimento da ditadura civil-militar (HALLEWELL, 2005).

Como as questões sociais e políticas deveriam ter, para o movimento ecumênico brasileiro baseado na responsabilidade sociopolítica cristã, uma

\footnotetext{
${ }^{3}$ A Conferência Mundial de Igreja e Sociedade, promovida pelo Conselho Mundial de Igrejas, foi um importante evento do movimento ecumênico mundial, reunindo mais de 400 delegados de igrejas cristãs de mais de 80 países e também observadores católicos. Seu conteúdo é considerado um paradigma na reflexão sobre a responsabilidade sociopolítica dos cristãos. Waldo César participou da conferência como correspondente do Jornal do Brasil (Cf. CEI, n. 13, jun. 1966) e produziu um artigo para a revista Paz e Terra intitulado "Os cristãos na revolução tecnológica e social do nosso tempo: uma interpretação da Conferência Mundial de Igreja e Sociedade". (PAZ E TERRA, n. 3, 1967, p. 165-180).
} 
abordagem ou interpretação religiosa, o alcance da editora Paz e Terra ganhou muita amplitude. Entre os autores estavam muitos nunca antes traduzidos para o português, entre eles Harvey Cox, Roger Garaudy, Oscar Cullman, Jean Lacroix, Lucien Goldmann, Simone de Beauvoir, Jean-Paul Sartre, Hebert Marcuse, Thomas Altizer, William Hamilton, Dietrich Bonhoeffer e Paul Tillich. Eram publicados também brasileiros como Paulo Freire, Hélio Jaguaribe, Carlos Nelson Coutinho.

A revista Paz e Terra foi publicada por três anos (1966-1969), com dez exemplares. Foi encerrada pelo fato de a editora não ter suportado financeiramente o recolhimento de vários números pela censura. Antes disso, porém, houve um impacto negativo na produção da revista: o desligamento de Waldo César da direção, o que foi comunicado aos leitores por ele mesmo, sem muita explicitação das razões, em nota na edição de número 9:

Com este número termino minhas atividades como diretor desta revista. Deixo registrado meu reconhecimento a todos aqueles que confiaram e cooperaram com esta proveitosa experiência cultural e ecumênica - tanto os leitores como os membros do Conselho de Redação - e faço votos de que o debate aberto e honesto entre os homens de boa vontade conforme a experiência destes anos. (PAZ E TERRA, out. 1969, p. 1).

Em nota assinada por Moacyr Félix na mesma página é registrado: "Circunstâncias de sua vida particular tornam impossível a nosso querido amigo Waldo César continuar dando a esta revista a valiosa colaboração que nos prestou ao longo de quase três anos”.

Não é difícil concluir que as "circunstâncias da vida particular" a que Félix se refere, estão relacionadas à prisão de Waldo César, no final de 1967: o sociólogo evangélico teve sua casa invadida pelo DOPS (Departamento de Ordem Política e Social) e, levado preso, esteve incomunicável por uma semana. ${ }^{4}$ Em 1968, ano do seu desligamento da revista, houve nova tentativa de prisão: "Vieram me buscar de

\footnotetext{
${ }^{4}$ A prisão foi comunicada no boletim CEI, n. 20, mar. 1967. De acordo com Waldo César, não houve tortura física e sim psicológica. Seus livros e documentos foram apreendidos, entre eles: $O$ conceito marxista do homem, de Erich Fromm; A invasão da América Latina, de John Gerassi; exemplares de Refórme (órgão da Igreja Protestante Francesa), de Cristianismo e Sociedade (revista de ISAL) e do CEl; e todos os documentos preparatórios da Conferência Mundial de Igreja e Sociedade.
} 
novo, mas eu dei o fora um dia antes. O primeiro foi o Dops, mas o segundo era mais sério, era com o Exército. Eu fiquei fora do Rio dois meses e consegui escapar” (CUNHA, 1997, p. 162).

A prisão de Waldo César repercutiu no movimento ecumênico da América Latina, como se pode constatar na carta do secretário-executivo da organização Igreja e Sociedade na América Latina, Luiz Odell, endereçada aos membros do Comitê Executivo da organização.

Nos últimos dias de fevereiro Waldo César foi preso, permanecendo nesta condição por quase uma semana. Ele foi acusado de estar dirigindo um protesto da Associação de Estudantes Secundários. Waldo disse que em geral foi bem tratado, que aproveitou a experiência para dizer-lhes algumas coisas e que finalmente terminaram pedindo-lhe desculpas. Parece que houve uma denúncia contra ele, presumivelmente de origem presbiteriana e a partir daí a polícia militar agiu. (...) [Sobre os livros apreendidos] Waldo disse a eles que deveriam levar também a Enciclopédia Britânica, já que nela havia mais informações sobre Marxismo que em qualquer outra parte! (...) O pastor Domício Mattos deu uma entrevista à imprensa e denunciou o ocorrido com Waldo e a perseguição que outros dirigentes presbiterianos estavam sofrendo. (CUNHA, 1997, p. 163).

Na memória de Waldo César, a revista e a editora Paz e Terra estavam relacionadas à prisão:

Quando fui preso, um dos assuntos era esse [a Paz e Terra]. (...) A editora Paz e Terra sobrevive, mas não tem mais nada a ver com o passado. $\mathrm{O}$ Gasparian comprou do Ênio. Hoje ele edita coisas boas, mas não tem aquele compromisso ecumênico. A Paz e Terra era uma editora ecumênica. (CUNHA, 1997, p. 175).

A editora Paz e Terra foi vendida em 1975 ao ex-líder estudantil e empresário paulista Fernando Gasparian (1930-2006), proprietário do jornal semanário de oposição Opinião. Já a Editora Civilização Brasileira também enfrentou muitos problemas diante de obstáculos criados ao seu funcionamento pelo regime militar. Foram muitas as ações policiais, jurídicas e econômicas contra a editora e contra Ênio Silveira. Ela começou a ser vendida em 1982, inicialmente por partes, em sociedade, envolvendo as editoras Difel e Bertrand Brasil, que também terminaram por enfrentar dificuldades financeiras e tudo foi vendido à Editora Record em 1997, um ano depois da morte de Silveira (HALLEWELL, 2005; ROSA, 2011). 
Depois do desligamento de César, a revista ainda teve um exemplar publicado, o décimo, dirigido por Moacyr Félix, com a data de dezembro de 1969.

A produção da revista Paz e Terra deve-se muito à postura política de Ênio Silveira, entusiasta e comprometida com a busca do bem-comum e seus ideais, mas também ao pensamento progressista de evangélicos e de católicos ligados ao CEI. Nas palavras de Waldo César:

Paz e Terra cultivava o que se podia denominar "ecumenismo secular". Seu corpo de redação era formado por protestantes (maioria), católicos e não-cristãos, com análises pontuais sobre o Brasil e a realidade internacional, levando-nos a cruzar, por vezes com assombro, essas "paragens não eclesiásticas" (expressão de Gustavo Gutiérrez). A editora [Paz e Terra] também traduziu e publicou dezenas de livros de teólogos contemporâneos. De toda maneira vivíamos a frustração da igreja que poderia ter sido e que não foi, parodiando o poeta Manuel Bandeira. (SOCIÓLOGO, 2007, on-line).

\section{0 acervo da revista Paz e Terra: um lugar de memória da comunicação religiosa durante a ditadura civil-militar no Brasil}

Com formato livro, contendo 13-15 artigos e média de 300 páginas, Paz e Terra era vendida com sucesso em livrarias e em bancas de jornais. De acordo com Waldo César, "embora tenazmente perseguida, foi grande o sucesso e a repercussão dessa aventura editorial (...) ela se esgotava rapidamente nas bancas de jornais e nas livrarias" (CESAR, 1998, p. 416).

O primeiro número de Paz e Terra não tinha um tema central; isto passou a ser a prática editorial a partir do segundo número. O corpo de dez edições tem o seguinte quadro:

TABELA 1 - Edições da Revista Paz e Terra e temas e autores publicados

\begin{tabular}{|l|l|l|l|}
\hline o & Data & $\begin{array}{l}|c| \\
\text { Tema } \\
\text { central e número } \\
\text { total de textos } \\
\text { assinados }\end{array}$ & Autores publicados no exemplar (**) \\
\hline
\end{tabular}




\begin{tabular}{|c|c|c|}
\hline Julho de 1966 & Sem tema central & $\begin{array}{l}\text { Alceu de Amoroso Lima; Conrado Eggers Lan; } \\
\text { Gonzalo Castilho C.; Dom Helder Câmara; Padre } \\
\text { Henrique C. de Lima Vaz; HiberConteris; Jean } \\
\text { Lacroix; José Honório Rodrigues; Linus Paulling; } \\
\text { Luiz Alberto Gomes de Sousa; Luiz Eduardo W. } \\
\text { Wanderley; Martin Luther King; Moacyr Félix; } \\
\text { Nestor Raúl Garcia; Paul Lehmann; Paul Tillich; } \\
\text { Papa Paulo VI; Pietro Nenni; Richard Shaul; } \\
\text { VijalaLaksshmi; Waldo A. César }\end{array}$ \\
\hline $\begin{array}{l}\text { Setembro de } \\
1966\end{array}$ & $\begin{array}{l}\text { História } \\
24 \text { textos }\end{array}$ & $\begin{array}{l}\text { Alberto SalváContel; Conrado Detrez; Donald } \\
\text { Duncan; Frei Eliseu Lopes; Padre Henrique C. de } \\
\text { Lima Vaz; Hugo Weiss; Jack Raymond, } \\
\text { Julio de Santa Ana; Lauro de Oliveira Lima; } \\
\text { Leandro Konder; Luiz Eduardo W. Walderley; Maria } \\
\text { Helena Kühner; Otto Maria Carpeaux; Paul Ricouer }\end{array}$ \\
\hline $\begin{array}{l}\text { Sem data } \\
(1967 ?)\end{array}$ & $\begin{array}{l}\text { Juventude } \\
\text { o8 textos }\end{array}$ & $\begin{array}{l}\text { Ângela Neves, Frei Carlos Alberto Cristo [Frei } \\
\text { Betto], Conrado Detrez, J. Kosinski Cavalcanti, } \\
\text { Jacqueline Skiles, Jovelino Ramos, Pamela Mills } \\
\text { Pierre Furter. }\end{array}$ \\
\hline $\begin{array}{l}\text { Agosto de } \\
1967\end{array}$ & América Latina & $\begin{array}{l}\text { Brady Tyson, Carl Oglesby, Carlos Drummond de } \\
\text { Andrade, Celso Furtado, HiberConteris, Hector } \\
\text { Borrat, [Monsenhor] Ivan Illich, Deputado Mata } \\
\text { Machado, Moacyr Félix, Noronha Filho, Pablo } \\
\text { Piacentini, Paul Tillich, Frei Pedro Secondi, Ramon } \\
\text { Ramirez Gomez, Padre Raymundo Ozanam de } \\
\text { Andrade, Richard Shaull, Frei Romeu Dale, } \\
\text { Warwick Estevan Kerr. }\end{array}$ \\
\hline $\begin{array}{l}\text { Outubro de } \\
1967\end{array}$ & $\begin{array}{l}\text { Sexualidade } \\
15 \text { textos }\end{array}$ & $\begin{array}{l}\text { A. Bernando Peres, André Dumas, Frei Eliseu Lopes, } \\
\text { Fernando Mendes Viana, D. Helder Câmara, } \\
\text { Monsenhor Ivan Illitch, Jean Brun, José Honório } \\
\text { Rodrigues, Leônidas R. Xausa, Maria Helena } \\
\text { Kühner, Michel Dufrenne, Nelson Pilosof, Paul } \\
\text { Ricouer, Paul-Louis Landsberg, Yvon Brés. }\end{array}$ \\
\hline Abril de 1968 & $\begin{array}{l}\text { Cristianismo em } \\
\text { questão }\end{array}$ & $\begin{array}{l}\text { Padre Camilo Torres, Danilo Zolo, [Frei] Francisco } \\
\text { C. Rolim, Francisco Carvalho, [Padre] Henrique C. } \\
\text { de Lima Vaz, Jovelino Pereira Ramos, Luiz }\end{array}$ \\
\hline
\end{tabular}




\begin{tabular}{|c|c|c|c|}
\hline & & 09 textos & Maranhão, Pierre Furter. \\
\hline & $\begin{array}{l}\text { Abril } \\
1968 ?\end{array}$ & $\begin{array}{c}\text { Violência-Não } \\
\text { Violência o9 textos } \\
\qquad\left(^{*}\right)\end{array}$ & $\begin{array}{l}\text { Bertrand Russel, Ernst Bloch, Francisco } \\
\text { Carvalho.Frei Francisco de Araújo, George } \\
\text { Hourdin,Padre [?] Helder Câmara, [Monsenhor] } \\
\text { Ivan D. Illich, John Gerassi, John M. Swomley Jr., } \\
\text { Jovelino P. Ramos, Karl Barth, Pierre Furter, [Frei] } \\
\text { Raymond Domergue, Padre Tomás Melville. }\end{array}$ \\
\hline & $\begin{array}{l}\text { Setembro de } \\
1968\end{array}$ & $\begin{array}{l}\text { Homem, Ciência e } \\
\text { Tecnologia } \\
11 \text { textos }\end{array}$ & $\begin{array}{l}\text { Alfredo Marques, Cláudio Santoro, H. M. } \\
\text { Nussenzveig, J. Leite Lopes, Prof. Mario Schenberg, } \\
\text { Murillo Nunes de Azevedo,Oscar J. Maggiolo, Paul } \\
\begin{array}{l}\text { Ricouer, [Frei] R. Simon,Rubem A. Alves, } \\
\text { YvanSimonis. }\end{array}\end{array}$ \\
\hline & $\begin{array}{l}\text { Outubro } \\
1969\end{array}$ & $\begin{array}{c}\text { Educação em Debate } \\
\text { o9 textos }\end{array}$ & $\begin{array}{l}\text { André Dumas, C. A. von Persen, Dom Helder } \\
\text { Câmara, Jayme Abreu, Marcel de Clerk, Michael } \\
\text { Klare, Néstor García Canclini, Paul Ricouer, Paulo } \\
\text { Freire, Pierre Furter. }\end{array}$ \\
\hline $\mathrm{O}$ & $\begin{array}{l}\text { Dezembro de } \\
1969\end{array}$ & $\begin{array}{c}\text { Fascismo em } \\
\text { Portugal } \\
\text { 10 textos }\end{array}$ & $\begin{array}{l}\text { Afonso Henriques Sacramento,Anders Johanssen,D. } \\
\text { Antônio Ferreira Gomes, Augusto Aragão, Basil } \\
\text { Davidson,Joaquim Barrados de Carvalho, Maria } \\
\text { Antônia Fiadeiro, Mário Mourinho de Pádua, } \\
\text { Miguel Urbano Rodrigues, Vitor Ramos. }\end{array}$ \\
\hline
\end{tabular}

\section{Fonte: Coleção da revista}

(*) Neste exemplar há o resultado de uma enquete com intelectuais brasileiros que resultou na publicação de 17 pequenos textos, o que está exposto adiante.

${ }^{* *}$ ) A grafia aqui reproduz a forma como o nome foi publicado. As indicações entre colchetes são titulações ou "apelidos" do autor citados em outros exemplares da revista

Ainda que tivesse temáticas centrais desde o primeiro número, os textos de Paz e Terra eram organizados em seções. No $\mathrm{n}^{0} 1$ constam três seções: Apresentação, Artigos e Documentário (que incluía indicações bibliográficas e resenhas de obras de interesse). Do $\mathrm{n}^{0} 2$ até o $\mathrm{n}^{0} 8$, vigoraram as mesmas seções: Apresentação, Tema, Temas Vários, Igreja e Diálogo e Documentário. Nos $\mathrm{n}^{\circ} \mathrm{s} 9 \mathrm{e}$ 10 as seções foram descartadas, sendo mantidas as indicações bibliográficas e resenhas sob o título "Perspectiva sobre o mundo dos livros". Havia espaço para charges em determinados números, algumas delas assinadas pelos artistas Jaguar e 
Claudius Ceccon (fundadores do clássico jornal Pasquim), este último com estreitas relações com o Centro Ecumênico de Informação e o Conselho Mundial de Igrejas.

A seção Apresentação, à exceção dos números 1, 4 e 5, introduzia a temática central e registrava a busca permanente pelo diálogo ecumênico, explicitada nas ênfases dadas ao Concílio Vaticano II, pelo segmento católico, e às ações do Conselho Mundial de Igrejas, pelo segmento evangélico.

Diálogo, que é a marca e a feição da revista: Igreja, um ponto de referência e de partida para a humanização e o próprio dialogo, tanto do lado católico-romano (Concílio Vaticano II), como protestante (Conselho Mundial das Igrejas). (PAZ E TERRA, n. 2, 1966, p.3).

A seção Documentário, por sua vez, foi bastante destacada na revista, pois trazia indicações bibliográficas e a reprodução de documentos, cartas, discursos, conferências e manifestos de lideranças e grupos religiosos referentes a questões intra e extra igrejas e instituições. A direção da revista justificava que tais textos, muitos identificados como "denúncia, diálogo e engajamento na realidade concreta do País, de testemunho de um cristianismo vivo que conhece os riscos da morte e da ressurreição", era a concretização da política editorial da revista (PAZ E TERRA, n. 6,1968, p. 149).

Há um amplo mosaico de autores com os mais diferentes engajamentos na academia e nos movimentos sociais. A maior parte deles tinha relação com as igrejas católica e evangélicas, respaldando a política editorial. Lideranças religiosas identificadas por suas posturas políticas de ênfase na justiça e na humanização foram autores publicados em mais de um número, como o arcebispo católico de Olinda e Recife D. Helder Câmara ("Manifesto dos Bispos do Nordeste", n. 1, 1966; "Imposições da solidariedade universal", n. 5, 1967; "Única opção: a violência?, n. 7, 1967, "Desafio que honra uma geração", n. 9, 1969) e o pastor batista estadunidense Martin Luther King ("Carta a amigos de bom senso", PAZ E TERRA, n. 1, 1966; capa do n. 7, "Violência e não violência", 1968). O assassinato de King também foi destacado em dois textos no exemplar de número 6, de abril de 1968. 
O objetivo do diálogo e do intercâmbio estabelecia a busca pela pluralidade de abordagens, o que levou a uma participação de autores que trouxeram à revista traços do diálogo inter-religioso. Este que era uma prática ainda incipiente no movimento ecumênico mundial e no próprio Conselho Mundial de Igrejas, foi conteúdo destacado nas páginas de Paz e Terra. O acervo contou com abordagens como: "Espiritismo e Participação", por Noronha Filho (nº 4, agosto 1967); "O ponto de vista Quaker a respeito do sexo”, tradução de pesquisa médica publicada na Grã Bretanha publicada na revista Current em maio de 1963 ( $\mathrm{n}^{\circ}$ 5, outubro de 1967); "O enigma de Martin Buber ao enigma de ser judeu”, por Nelson Pilosof (no 5, outubro de 1967); "Um mergulho no real: budismo", por Murillo Azevedo (n 8, setembro de 1968).

Também na linha de intercâmbio e diálogo, Paz e Terra dedicava páginas a traduções de materiais publicados em outros periódicos, aos quais leitores brasileiros não teriam fácil acesso. Textos de revistas e jornais franceses, estadunidenses e latino-americanos foram publicados. Nesta direção, reproduções de textos de revistas e jornais brasileiros eram incluídas. Os dois primeiros números registraram a colaboração de correspondentes internacionais: Richard Shaull (teólogo, ex-missionário presbiteriano no Brasil, sediado nos Estados Unidos); André Dumas (pastor da Igreja Reformada da França); Hiber Conteris (educador, integrante de Igreja e Sociedade na América Latina no Uruguai); Gonzallo Castillo Cárdenas (pastor presbiteriano da Colômbia); Hector Borrat (advogado católico do Uruguai). A revista não deixa claro o papel desses correspondentes, cuja menção desaparece a partir do $\mathrm{n}^{\mathrm{o}} 3$, mas todos eram vinculados a periódicos de perfil semelhante à Paz e Terra em seus países e alguns deles tiveram artigos assinados na revista.

Paz e Terra inovava na busca do diálogo e do intercâmbio de ideias, o que fez da revista também um fórum de reflexões. No $n^{0} 7$, de 1968, com o tema central "Violência e Não-Violência", tendo na capa uma imagem de Martin Luther King, foram publicados 17 pequenos textos resultantes de uma enquete intitulada "Intelectuais Brasileiros e a violência”, de "várias correntes de pensamento", com a 
pergunta: "Em que medida seria legítimo o uso da violência na transformação da sociedade?" Os 17 textos representavam as respostas recebidas (membros dos conselhos de revistas da Editora Civilização Brasileira, lideranças cristãs e intelectuais). Em comum havia o reconhecimento da legitimidade de ações violentas quando usadas para a libertação de grupos sociais que enfrentassem situações desumanizantes, de ameaça à vida. Responderam à revista: Antonio Houaiss, Barbosa Lima Sobrinho, Breno Schumann, Dias Gomes, Frei Eliseu Lopes. [Rev.] Glauco S. de Lima, Hélio Pelegrino, Hélio Silva, [Frei] Henrique de Lima Vaz, Rev. J. C. Maraschin, Jorge Amado, José Honório Rodrigues, Maria Yeda Linhares,Miguel Urbano Rodrigues, Otto Maria Carpeaux, Padre Orlando Maia, Frei Pedro Secondi.

Como a pesquisa pode constatar, a publicação de autores renomados relacionados a vários campos de ação, identificados com o "humanismo cristão", a abertura para temáticas incomuns no repertório de publicações religiosas com ênfase no diálogo e no intercâmbio de ideias são elementos afirmativos da relevância desta publicação como iniciativa ímpar dos anos 1960, no campo da comunicação religiosa, ecumênica e política. Ela só foi possível por conta da aproximação do grupo de lideranças religiosas ecumênicas do Centro Ecumênico de Informação com o editor militante de esquerda Ênio Silveira e suas ousadias intelectuais.

\section{A título de conclusão}

A articulação da narrativa da memória da revista Paz e Terra com a descrição do conteúdo dos dez exemplares publicados de 1966 a 1969 torna possível afirmar a relevância desta publicação no campo da comunicação religiosa brasileira, particularmente a evangélica e a ecumênica.

Ao ser limitadamente identificada como uma "publicação de Ênio Silveira", em muitos materiais biográficos e estudos sobre a Editora Civilização Brasileira, Paz e Terra tem um importante elemento de sua identidade apagado da memória 
da editoração brasileira: é uma revista religiosa. Suas páginas guardam textos de qualidade acadêmica, produzidos por intelectuais de renome, e também a memória de um movimento religioso que marcou sua época, pois dialogava e atuava com segmentos sociais não religiosos, até mesmo aqueles formados por ateus, como Ênio Silveira.

Suporte na conservação e disseminação da memória de evangélicos identificados com movimentos de responsabilidade sociopolítica cristã, em especial com o movimento ecumênico nacional e internacional, Paz e Terra registra o pensamento de uma época, especialmente aquele dos produtores da revista que selecionavam e editavam esses textos preocupados com reflexões densas, com base na perspectiva do diálogo e do intercâmbio de ideias, e em seu engajamento social que enfatizava a paz com justiça na terra. Nesse sentido, a reflexão de Fentress e Wickham (1992) introduzida neste artigo, de que linguagem, ideias coletivamente assumidas e experiências partilhadas constroem memória social, é concretizada no projeto de Paz e Terra.

Nesta direção, é possível afirmar Paz e Terra como lugar da memória da comunicação religiosa política progressista no Brasil durante o período da ditadura militar. Os registros da revista a transcendem, conformam sua aura, e se tornam espaços de fixação da memória e atuam como novas formas de transmissão. É um lugar que permite que quem nunca viveu o que ali está registrado assimile esta memória, ou seja, produz uma memória herdada pelo movimento ecumênico nacional, com a qual evangélicos progressistas e identificam e podem ser identificados.

A premissa assumida neste artigo de que as mídias são lugares de memória, se afirmam com a exposição descritiva do que foi e permanece sendo a revista Paz $e$ Terra, como registro, arquivamento, propagação de narrativas. Por isso, o protestantismo e o movimento ecumênico no período da ditadura militar no Brasil deixam de ser matéria apenas para museus, arquivos, monumentos e túmulos. As páginas de Paz e Terra não tratam apenas desse passado, mas fazem emergir os 
sentidos no presente e provocam a instituição de novas memórias. São, portanto, lugares componentes de um processo de construção da memória social e importante suporte para se conhecer uma parcela do segmento evangélico no Brasil, por muitos ignorada e que instiga a novos estudos e reflexões.

\section{REFERÊNCIAS}

CESAR, Waldo A. Uma vocação ecumênica. In: FÉLIX, Moacyr (org.). Ênio Silveira: arquiteto de liberdades. Rio de Janeiro: Bertrand Brasil, 1998.

COMISSÃO NACIONAL DA VERDADE. Relatório. Brasília: CNV, 2014. Vols. I, II e III. Disponível em: < http://cnv.memoriasreveladas.gov.br/>. Acesso em 22 set 2020.

CUNHA, Magali N. Crise, esquecimento e memória. O Centro Ecumênico de Informação e a construção da identidade do Protestantismo Brasileiro. Dissertação (Mestrado em Memória Social e Documento). Universidade do Rio de Janeiro, 1997.

CUNHA, Magali N. Explosão gospel: um olhar das ciências humanas sobre o cenário evangélico brasileiro. Rio de Janeiro: MAUAD, 2007.

FÉLIX, Moacyr (org.). Ênio Silveira: arquiteto de liberdades. Rio de Janeiro: Bertrand Brasil, 1998.

GLENISSON, Jean. Iniciação aos estudos históricos. São Paulo: Difel, 1961.

GUARINELLO, Norberto Luiz. Memória coletiva e história científica. Revista Brasileira de História, São Paulo, Espaço Plural, v. 14, n. 28, p. 180-193, 1994. Disponível em: $<$ https://revista.historiaoral.org.br/index.php?journal=rho\&page=article\&op=download\& path\%5B\%5D=25\&path\%5B\%5D=19>. Acesso em 22 set 2020.

HALBWACHS, M. Les cadres sociaux de la mémoire. Paris: Felix Alcan, 1925.

HALLEWELL, Laurence. O livro no Brasil: sua história. São Paulo: Edusp, 2005.

LE GOFF, Jacques. História e memória. Campinas: Unicamp, 1994.

MENDONÇA, Antônio Gouveia. O celeste porvir. A inserção do protestantismo no Brasil. São Paulo: Paulinas, 1984.

NORA, Pierre. Entre memória e história: a problemática dos lugares. Projeto História. São Paulo, n. 10, p. 7-28, dez 1993. Disponível em: $<$ https://revistas.pucsp.br/index.php/revph/article/view/12101>. Acesso em 22 set 2020. 
PAZ E TERRA, Rio de Janeiro: Editora Civilização Brasileira, n. 1-10, 1966-1969.

RIBEIRO, Ana Paula Goulart, FERREIRA, Lucia Maria Alves (orgs.). Mídia e Memória. A produção de sentidos nos meios de comunicação. Rio de Janeiro: Mauad X, 2007.

RIDENTI, Marcelo. Em busca do povo brasileiro: artista da revolução, do CPC à era da TV. Rio de Janeiro: Ed. Record, 2000.

RIVERA, Dario Paulo Barrera. Linguagem, memória e religião no pensamento de Maurice Halbwachs. Horizonte: Revista de Estudos de Teologia e Ciências da Religião, v. 16, n. 51, p. 1177, 31 dez. 2018. Disponível em:

<http://periodicos.pucminas.br/index.php/horizonte/article/view/P.21755841.2018v16n51p1177/14256>. Acesso em: 22 set. 2020.

ROSA, Michele Rossoni. "Esquerdisticamente afinados": os intelectuais, os livros e as revistas das Editoras Civilização Brasileira e Paz e Terra (1964-1969). (Doutorado em História). Universidade Federal do Rio Grande do Sul, 2011. Disponível em <http://www.lume.ufrgs.br/handle/10183/31727>. Acesso em: 22 set. 2020.

SOCIÓLOGO relembra a abertura dos evangélicos para a realidade social brasileira nos anos 60. Ultimato, n. 305, mar-abr 2007. Disponível em <http://www.ultimato.com.br/revista/artigos/305/sociologo-relembra-a-abertura-dosevangelicos-para-a-realidade-social-brasileira-nos-anos-6o>. Acesso em: 22 set. 2020. 